\title{
FACILITATING RESULTS-BASED PLANNING IN DEVELOPING COUNTRIES: THE CASE OF VIETNAM'S MINISTRY OF AGRICULTURE AND RURAL DEVELOPMENT
}

\author{
Pham Ngoc Ha \\ Ph.D., Lecturer, Vietnam National Academy of Public Administration. \\ Address: 77 Nguyen Chi Thanh, Hanoi, Vietnam. \\ E-mail: hapn@napa.vn; pnh237@gmail.com
}

\section{Nguyen Thi Hong Hai}

Ph.D., Associate Professor, Head of Faculty of Administrative Sciences and Organization and Personnel Management, Vietnam National Academy of Public Administration.

Address: 77 Nguyen Chi Thanh, Hanoi, Vietnam.

E-mail: hunghai2002vn@yahoo.com

\begin{abstract}
Over the past decade, there has been an increased use of results-based management in Vietnam and other countries, but little empirical research exists on resultsbased planning (RBP). This research empirically examines the impact of four organizational factors on the outcomes of RBP. Data were based on 177 respondents from the Ministry of Agricultural and Rural Development - one of the pioneering government agencies adopting RBP in Vietnam. This study finds that employee commitment and RBP-related training have a direct, positive, and strong effect on the outcomes of RBP, and leadership support and involvement, donor support indirectly affect RBP outcomes via employee commitment. This study contributes to the literature by offering empirical evidence of the role of organizational factors in implementing reforms such as RBP in the context of a developing country. Some recommendations for furthering such reforms are also made.
\end{abstract}

Keywords: results-based planning; reforms; commitment; RBP outcomes; leadership support and involvement; donor support; training.

Citation: Pham Ngoc Ha \& Nguyen Thi Hong Hai (2020). Facilitating ResultsBased Planning in Developing Countries: The Case of Vietnam's Ministry of Agriculture and Rural Development. Public Administration Issues, no 5, (Special Issue I, electronic edition), pp. 59-80 (in English); DOI: 10.17323/1999-5431-2020-0-5-59-80 


\section{Introduction}

Over recent decades, there has been an increasing interest in results-based management among developing countries in terms of reforming their public sectors (Asia-Pacific CoP-MfDR, 2011; Middleton \& Regan, 2015; OECD-DAC, 2007). Results-based management approach aims at improving management effectiveness and accountability (Curristine, 2005; OECD, 2011). It is suggested that results-based management principles should apply to every stage of public sector management (planning, programming, budgeting, implementation, monitoring and evaluation) and be placed in a country context at various levels (national, subnational, sectoral and organizational) (Asia-Pacific CoP-MfDR, 2011; Middleton \& Regan, 2015).

In many non-Western developing countries including Vietnam, development planning has been one of the key policy instruments for central governments (Forsberg, 2007; Tan, 2012). Results-based planning (RBP) is expected to help improve development planning processes in such countries. In this article, RBP refers to the application of results-based management principles within the planning processes of public agencies to achieve desired outcomes.

Past studies have found that there are many factors affecting results-based management such as leadership, stakeholder and employee commitment and involvement, resources, and organizational culture, staff competence, etc. (de Waal and Counet, 2009; Mayne, 2007; Asia-Pacific CoP-MfDR, 2011). However, empirical research on RBP outcomes and its determinants in the context of nonWestern developing countries is relatively scarce. In other words, there remains a lack of a robust knowledge base that organizations in such countries can rely upon to effectively implement RBP. This research seeks to answer the following research question: how do organizational factors influence the outcomes of RBP? This study used both surveys and in-depth interviews with 177 public managers and employees from the Ministry of Agricultural and Rural Development (MARD) - one of the pioneering government agencies adopting RBP in Vietnam.

This study adds to the performance management literature by examining and providing empirical evidence of the relationships between organizational factors and the outcomes of results-based reforms such as RBP in a context of a developing country. Moynihan (2006) describes the adopted reforms of the last quarter of the $20^{\text {th }}$ century as giving birth to an "era of government by performance management", however, while the most valuable studies offer fruitful information on results-oriented reforms in the most advanced nations such as the USA and UK, only limited perspectives of these movements have been discussed in the developing world so far (Moynihan et al, 2011; Gerrish, 2016; Pollitt and Dan, 2013; Gao, 2015).

In particular, our knowledge of results-based management practices as well as the actual outcomes of performance management in both developed and developing countries remains limited (Nielsel, 2014; Gao, 2015; Poister et al, 2013). Practically, this study offers public organizations some useful sug- 
gestions on which organizational factors should be focused to further resultsbased reforms.

The study setting involves the Vietnam Ministry of Agriculture and Rural Development (MARD) - one among several pioneering and successful government agencies that have been implementing RBP so far. Vietnam has a tradition of five-year national development plans which provide general development orientation for the whole country and are consolidated from local and sector development plans at all lower levels (Vu, 2008; Tan, 2012; OECD, 2013; $\mathrm{ADB}, 2015)$.

As a result of the growing awareness within the government of the limitations of traditional planning (e.g. unclarity of development objectives, weak linkages of planning and budgets, etc.) which lead to the non-transparent and inefficient use of public resources and difficulties in conducting performance monitoring and evaluation, development planning processes have seen considerable reforms take place since 2001 (OECD-DAC, 2007). Over the past ten years, with the support of many internationally-funded projects - for example, the Asian Development Bank $(\mathrm{ADB})$ provided technical assistance for the preparation and implementation of the results-based socio-economic development plan 2011-2015 (ADB, 2015) - a number of provinces and line ministries have been reforming the planning process with a results-based approach. It is worth noting that like other reforms, RBP follows the common characteristics of policy-making processes in Vietnam such as being a gradual and experimental process and being increasingly affected by external factors (e.g., international donors' influences) (Dang, 2013).

The Ministry of Agriculture and Rural Development (MARD) is a significant example. The planning reform with RBP in MARD is one of the few reform programs that have been successful in securing long-term sustainability by institutionalizing their program outputs and replicating pilot projects throughout the ministry. RBP was initially introduced as a planning reform by MARD in 2005. The main contents of this planning reform are to make their goals and means more unambiguous, focus on results, and be more closely linked to budgets, in which the development of a hierarchy of primary and secondary objectives is central (OECD-DAC, 2007; World Bank, 2011; Asia-Pacific CoP-MfDR, 2011).

So far, the adoption of RBP in government agencies has not been mandated by central government but rather voluntary and experimental. However, RBP in MARD is now mandatory for all of its subdivisions. Some key features of the results-based approach can be seen in its sectoral development plan 2016-2020. As shown in Figure 1, the overall sectoral development goal was to achieve "comprehensive agriculture, average incomes of families in rural areas increased, natural resources protected and effectively, sustainably exploited." This highest order objective was cascaded down to six specific objective-sector outcomes (e.g., sustained and quality growth in the sector through increased productivity and production quality) and to a set of sub-sector outcomes with relevant indicators and targets (e.g., increased fishery gross value-added ratio from 5.4\% in 2016 to $5.5-6 \%$ by 2020$)$. 


\section{Figure 1: Agriculture Sector Development Plan: Fisheries}

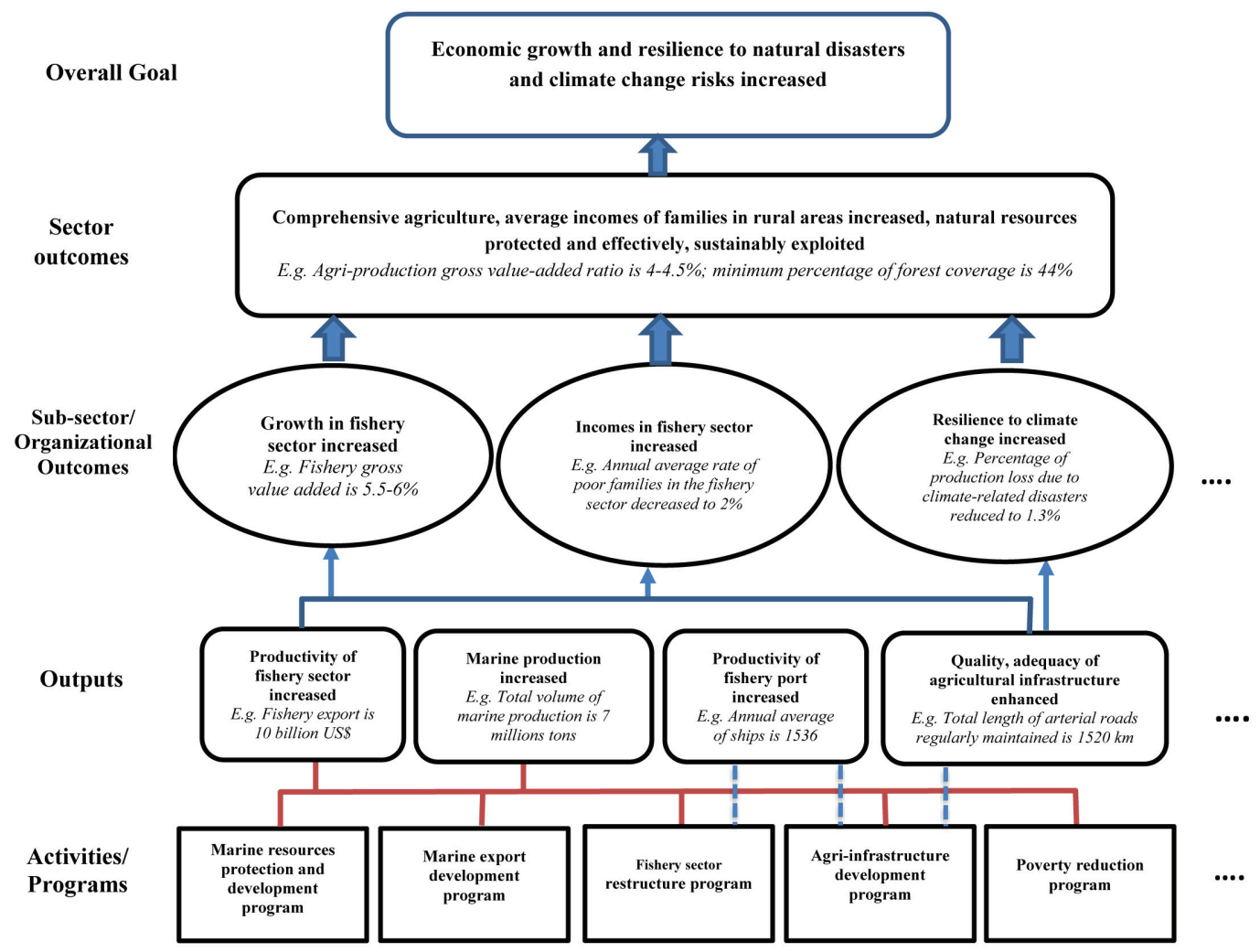

Discussions with a number of key informants in charge of making plans and actual observations in MARD find that leadership support and involvement, international donor support, employee commitment, and well-trained civil servants are key factors affecting RBP success, which are also recognized in other public reform initiatives in Vietnam (Do \& Truong, 2009; MOHA, 2015; Hung et al, 2015). The following section describes the conceptual framework developed for the study to investigate the relationships between organizational factors and RBP outcomes.

\section{Conceptual framework}

\section{RBP outcomes}

This study defines RBP as the application of results-based management principles within the planning process of public organizations. More specifically, RBP involves rigorous analysis of intended results cascaded down from macro-level impacts to specific sector outcomes. These results must be clearly defined within a budget envelope, with indicators and targets, and with relevant monitoring and evaluation frameworks (Asia-Pacific CoP-MfDR, 2011). RBP is expected to assist organizations in increasing goal/objective clarity, improving the quality and logic of their plans, fostering transparency and accountability, and evaluation of outcomes against desired objectives. 
After the economic reform, called Doi moi (Innovation) in 1986, in line with the transition from a centralized planning economy to a socialist-oriented market economy, some considerable changes have been made in Vietnamese development planning processes (e.g., inputs-production targets such as the types and the quantity of products needed to be produced are no longer emphasized). However, the planning process has so far still faced some limitations. To be specific, Vietnamese development plans still contain large lists of achievements, problems, objectives, targets, indicators, and things to do, without showing much connection between them. Very often, their goals and objectives are ambitious and weakly linked to corresponding programs and activities, and seldom are such goals operationalized into specific objectives which results in the low quality of and lack of logic in the development plans. These above limitations lead to difficulties for allocating resources and monitoring program performance and evaluation of actual achievement against any planned goals and objectives (OECD-DAC, 2007; Do \& Truong, 2009; OECD, 2013). Also, the ambiguity to the public on how development programs using public resources can be translated into actual outcomes and impacts that will benefit them, accompanied with the lack of an effective mechanism for coordinating the planning and budget processes lead to inefficient use of resources (Williams \& Cummings, 2005; Cox, 2011; Tan, 2012).

The adoption of RBP responds to such criticisms of conventional development planning. The difference is readily seen in Table 1.

Table 1

\section{Traditional Planning versus Results-Based planning}

\begin{tabular}{|c|c|c|}
\hline Dimensions & Traditional Planning & Results-Based Planning (RBP) \\
\hline Main focus & $\begin{array}{l}\text { Inputs, activities, outputs (process) } \\
\text { E.g. Funding for marine } \\
\text { infrastructure (inputs); volume } \\
\text { of marine production (outputs) }\end{array}$ & $\begin{array}{l}\text { Outputs, outcomes, impacts (results) } \\
\text { E.g., in addition outputs, marine resources } \\
\text { are protected; marine industry is safe } \\
\text { and sustainable (outcomes) }\end{array}$ \\
\hline \multirow[t]{2}{*}{ Process } & $\begin{array}{l}\text { Internal process (within agencies } \\
\text { and localities, with foci on the role } \\
\text { of planning units) } \\
\text { The analysis is based on official } \\
\text { data from government reporting } \\
\text { system }\end{array}$ & $\begin{array}{l}\text { Participatory process (stakeholder involvement) } \\
\text { The analysis is based on internal and external } \\
\text { sources, incl. independent survey data }\end{array}$ \\
\hline & $\begin{array}{l}\text { The translation of overall goals into } \\
\text { specific objectives is not clearly } \\
\text { shown }\end{array}$ & $\begin{array}{l}\text { The translation of overall goals into specific } \\
\text { objectives is clearly shown, identifying (sub) } \\
\text { sector outcomes, budget envelopes, indicators } \\
\text { and targets, and monitoring and evaluation } \\
\text { frameworks (results frameworks) }\end{array}$ \\
\hline \multirow{4}{*}{$\begin{array}{l}\text { Outcomes } \\
\text { of planning }\end{array}$} & Unclarity of development objectives & Increased the clarity of development objectives \\
\hline & $\begin{array}{l}\text { Lack of accountability and } \\
\text { transparency }\end{array}$ & Increased transparency and accountability \\
\hline & Low quality of development plans & Increased quality and logic of development plans \\
\hline & $\begin{array}{l}\text { Difficulty in monitoring the program } \\
\text { performance and evaluating actual } \\
\text { achievement with set development } \\
\text { goals and objectives }\end{array}$ & $\begin{array}{l}\text { Improved monitoring of program performance } \\
\text { and evaluation of outcomes against desired } \\
\text { development objectives }\end{array}$ \\
\hline
\end{tabular}


This study conceptualizes the construct "RBP outcomes" based on RBP definitions and its features generalized from the literature on results-based management- type reforms and applied studies on RBP, as well as the actual observation in Vietnam (as shown in Table 1). "RBP outcomes" here is referred to as a number of short-term or medium-term results that are produced by the implementation of RBP activities such as goal/objective clarity, improvement in the quality and logic of plans, fostered transparency and accountability, and evaluation of outcomes against desired objectives.

\section{Organizational factors affecting RBP outcomes}

Many key variables are most certainly related to performance management practices and are well documented in the literature, including leadership, organizational culture, financial problems, performance management related- training, the number of tasks an agency performs, agency size, stakeholder and employee participation, commitment, etc. (De Waal \& Counet, 2009; Heinrich, 2002; Mayne, 2007). However, no specific combination of factors has been offered which correctly forecast the success of performance management practices. Based on prior research findings and the practical evidence of the RBP adoption in the Vietnamese public sector as discussed in our introduction, four organizational factors that relatively influence RBP outcomes in Vietnam are sequentially examined in this study. They are (1) Leadership support and involvement; (2) RBP-related training; (3) International donor support; and (4) Employee commitment.

\section{Leadership support and involvement and RBP outcomes}

Leadership support and involvement is assumed to influence RBP outcomes. The literature as well as the practical evidence of recent public sector reforms in Vietnam have indicated the critical role of leadership, especially top leadership, in the process of change and reform in public organizations (Van Der Voet et al., 2014; Wong, 2013; Hung et al, 2013; Pham, 2018). Similarly, a bulk of evidence from the literature shows that senior leadership support for a results -based approach is likely the most frequent suggestion cited in the reports of many countries on results-based management experiences (Ariyachandra \& Frolick, 2008; Perrin, 2002; Mayne, 2007).

In Vietnam, very often top or senior public managers at all levels are generally responsible for the adoption of any reforms in their agencies/localities including results-based reform. Being commonly well respected and followed by organizational members due to the strong tradition of the high level of trust and obligation between leaders and followers, they are expected to help public agencies achieve positive outcomes of RBP, as widely recognized in many other public sector reforms (Pham, 2018). Indeed, during the adoption of RBP in public organizations, once top or senior managers indicate that RBP is worth considering as a high priority, and they are clearly and visibly involved not only in its initiation but also in its implementation (e.g., sending strong messages of support for RBP to their staff by giving speeches and notices, getting subordinate involvement in the process, keeping the pressure on operating units to work with RBP, encouraging followers to implement RBP, providing necessary help 
and resources, and devoting time to RBP process), the possibility of reaching the desired outcomes of RBP will be increased.

Based on the above-mentioned arguments, we hypothesize:

H1: Leadership support and involvement has a direct, positive effect on RBP outcomes

\section{$R B P$ related training and $R B P$ outcomes}

Practical evidence in Vietnam shows that providing training and guidance on specific reform programs to managers and employees significantly contributes to reform success. Undoubtedly, training provides managers and staff with the necessary knowledge, skills and abilities to develop and use policies/programs successfully (Schraeder et al, 2005). Over the past few years, thousands of Vietnamese civil servants at all levels, including managers and non-managers, have been sent on relevant training courses whenever a specific reform program is deployed (e.g. Project 30 on the simplification of administrative procedures, One-stop-shop model, Programs on IT application and development, etc.) (Hung et al, 2013; Pham, 2018). Similarly, providing RBP related-training for public servants who are involved in RBP implementation is of importance for its success.

It is worth noting that adopting a results-focus requires skills not used in past input-oriented plans, such as the ability to use different management techniques in collecting and using statistical data, monitoring performance on a variety of measures, reporting performance, and reevaluating strategies and targets based on performance information. In addition, to ensure clarity and common understanding of RBP, and then its successful implementation and use, training needs to be effective. RBP-related training is considered effective if (1) implementers are provided, through training courses, with the basic knowledge and skills of RBP (e.g., definition, benefits of results-based planning, problem tree analysis, objective tree analysis, logic model framework for planning); (2) the trainers are required to provide many excellent and real-life examples of RBP as well as encourage their trainees to raise any questions related to the application of RBP; and (3) the trainees can apply their knowledge and skills of RBP learned from training courses in their work.

Obviously, during the implementation of RBP, such effective training provided either by their superiors or relevant training institutes helps employees to get familiar with the basic concepts of RBP, and therefore understand more about the whole planning process and clearly know how to implement necessary steps, which enhances their confidence and acceptance of RBP and participation in RBP processes, leading to the achievement of desired outcomes of RBP such as increased clarity of plan objectives and increased quality, logic, and feasibility of plans. This argument is supported by clear evidence in the literature that the absence of effective training could hinder the success of performance management approaches (Ohemeng, 2009; De Waal \& Counet, 2009; Hung et al, 2015). Based on the above arguments, the following hypothesis will be tested:

$H 2$ : Effective training of RBP has a direct, positive relationship with RBP outcomes.

\section{International donor support and RBP outcomes}

External support acts as an important determinant of successful change efforts including performance management (Abramson \& Lawrence, 2001; Mayne, 2007; 
Fernandez \& Rainey, 2006). As discussed in our introduction, RBP was initially introduced in Vietnam by international donors as the technical and financial support for the implementation of its development planning reforms (Forsberg \& Kokko, 2007; Tan, 2012). Like other developing countries, due to the globalization trend, international ideas and practices related to public administration such as new public management, ISO accreditation and job description have been transferred to Vietnam in many ways (e.g., through international donors, NGOs) (Vasavakul, 2006). For example, the adoption of a new public management (NPM) approach including RBP in the Vietnamese public sector is mostly rooted in the impacts of successful reform experiences from Western countries and the encouragement of various international donors such as $\mathrm{WB}, \mathrm{UNDP}, \mathrm{ADB}$, etc., as it is in many other developing countries (Garcia Moreno \& Lopez, 2010; OECD-DAC, 2007).

Hence, it is argued that the success of RBP in the public sector in a developing country such as Vietnam partly depends on the degree of international donor support. According to Hung et al. $(2013,2015)$ and through practical observation in several Vietnamese public agencies that have been implementing results-based reforms such as RBP, international donors sometimes play a key role in getting such reforms adopted in agencies, but after such reforms commence, international donors often shift their support, technical and financial alike, to other agencies or projects, which leads to the failure or termination of reforms in certain public agencies.

To ensure RBP success, sufficient support from international donors, both technical and financial, is of necessity. This argument is supported by the recommendations on enhancing donor support to reform initiatives provided by OECD (2004), World Bank (2008), and Hung et al. (2013). The effects of international donors' support on the outcomes of RBP can be illustrated in the following ways: (1) providing technical and financial support to help the implementing agency's members to become familiar with RBP; (2) funding their initial efforts in RBP; and (3) partly ensuring the continued use of RBP in these agencies. This support helps increase employees' familiarity with and confidence in the new planning approach, thereby increasing employees' participation and involvement in RBP, resulting in reaching desired outcomes of RBP. Therefore, we hypothesize:

H3: Sufficient international donor support has a direct, positive effect on RBP outcomes.

\section{Employee commitment to RBP and RBP outcomes}

A number of previous studies indicate the positive association between employee commitment to change and the success or positive outcomes of change initiative (Herscovitch \& Meyer, 2002; Meyer, 2007; Jaros, 2010; Hill, 2012). Commitment to a change is defined as 'a mindset that binds an individual to a course of action deemed necessary for the successful implementation of a change initiative' and includes three dimensions: '(a) a desire to provide support for the change based on a belief in its inherent benefits (affective commitment to the change), (b) a recognition that there are costs associated with failure to provide support for the change (continuance commitment to the change), and (c) a sense of obligation to provide support for the change (normative commitment to the change)' (Herscovitch \& Meyer, 2002, p. 475). Herscovitch and Meyer (2002) suggest that all of these com- 
ponents should combine to influence employee behaviors in implementing change. In the case of RBP which is considered as a change in the planning approach, once employees feel a desire to cooperate with RBP based on their belief in its values (affective), think that it should be better for them to support RBP (continuance), and feel of sense of duty to work toward RBP (normative), they will participate in RBP processes more actively, resulting in the increased clarity of plan objectives and the increased quality and logic of plans. Thus, we hypothesize:

H4: Employee commitment to RBP has a direct, positive effect on RBP outcomes.

\section{Employee commitment as a mediating factor}

A review of previous studies finds a positive and significant relationship between training and employee commitment (Conway \& Monks, 2008; Ocen \& Angundaru, 2017; Nkosi, 2015). According to Conway and Monks (2008), training is one of the "top four" HRM practices positively affecting employee commitment to change. Indeed, training has a positive impact on affective commitment to RBP because training helps employees understand the benefits of RBP which leads to the feeling of desire to contribute to RBP, whereas training positively influences normative commitment as it emphasizes feelings of the necessity to reciprocate benefits accorded to employees by RBP. Also, training can affect continuance commitment to RBP because it helps employees recognize the costs associated with resisting change. Thus, there may exist a connection between RBP-related training and employee commitment to RBP, and outcomes of RBP in which employee commitment to RBP plays a mediating role. In other words, employment commitment to RBP is included as a potential mediator of the training - RBP outcomes relationship. Therefore, we hypothesize:

H4a: Employee commitment to RBP mediates the relationship between RBP-related training and RBP outcomes.

Similarly, past studies indicate the positive relationship of leadership practices and employee commitment to change (Herold et al, 2008; Wallace et al, 2013; Van der Voet et al, 2016). In the case of RBP, managers, by sending strong messages of support for RBP to their staff through giving speeches and notices, encouraging subordinates to implement the new approach, providing necessary help and resources, devoting time to the RBP process, and getting subordinate involvement in the process, can help to increase followers' awareness and understanding of the values of RBP to their organization as well as the personal benefits they can gain from RBP implementation, resulting in the feeling of desire (affective) to support RBP among employees. In addition, by keeping the pressure on operating units to work with RBP, managers can create the feeling of a sense of duty to work toward RBP (normative) and recognition among employees that it should be better for them to support RBP. This will lead to the compliance with the requirement of RBP which ensures that all necessary RBP activities are undertaken plus more participation in RBP processes, resulting in the increased clarity of plan objectives and the increased quality and logic of plans. Thus, this study hypothesizes:

H4b: Employee commitment to RBP mediates the relationship between leadership support and involvement and RBP outcomes. 
Also, practical observation in Vietnam shows that international donors, through their technical support such as providing employees with knowledge on RBP and coaching them how to use useful management techniques and tools in collecting and using statistical data, monitoring performance on a variety of measures (logical framework, objective tree analysis, etc.) can increase employee's awareness of the potential benefits. RBP can bring to their agencies and themselves, hence, creating the feeling of desire to support RBP (affective commitment) and the recognition of personal benefits associated with supporting RBP (continuance commitment). Moreover, through financial support by donors such as providing budgets for collecting and analyzing data, training, etc. employees can obtain certain benefits which help increase their commitment to RBP. Gilley (2005) finds that employees tend to commit more to the change if they can find personal benefits from change implementation. Hence, we hypothesize:

H4c: Employee commitment to RBP mediates the relationship between international donor support and RBP outcomes.

\section{Methods}

\section{Sampling and data collection}

This article focuses primarily on the Vietnam Ministry of Agriculture and Rural Development (MARD) which is one of the pioneering government agencies adopting RBP. The sample (both for the surveys and the interviews) consisted of public employees from MARD who are considered as the most knowledgeable about RBP and directly involved in its implementation and use. The sampling frame was constructed using the snowball sample technique which started with a collaboration with the staff from MARD's Planning Department who facilitated the researcher's access and provided us with a list of public managers and employees central to the agency's RBP practices. We then contacted those managers and employees and asked them to provide the information needed to locate other members directly involved in their organizations. As a result, 177 participants were identified.

Quantitative surveys and qualitative interviews were used in our twostage data collection. The first stage began with five interviews that assisted the researcher to further refine the survey questionnaire which was initially developed based on the literature review and pre-tested by two experts. In the following step, to test the clarity of the study as well as to avoid errors, a pilot survey was conducted with 25 randomly selected respondents. Based on the results of quantitative data analysis using SPSS 23, final revisions were made before conducting the main survey. Subsequently, of all 177 paper questionnaires distributed, 132 completed responses were returned within six weeks, giving a response rate of $74.6 \%$. The respondents have undergraduate degrees (76.6\%) and graduate degrees (16.6\%), and have been working for eight years in their organizations on average. This suggests that the respondents had sufficient knowledge and ability to understand and thus respond to the questionnaire appropriately. 


\section{Measures}

The survey included all the key variables measured on a fully anchored 5-point Likert scale including RBP outcomes and organizational factors as described in the framework. A detailed list of measures is shown in Appendix. The instrument for RBP outcomes was purposely developed for this research and based on Asia Pacific CoP-MfDr (2011), Middleton and Regan (2015) and the results of pre-survey interviews. This term is defined as the actual benefits results-based approach brings to the planning process. The scale for this construct includes six items. The example item is "As a result of using results-based planning in my unit, we increased the clarity of our objectives." RBP-related training involves a newly developed set of four items (after removing two items with low outer weight). The example item is "I was provided by training courses with basic knowledge and skills of results-based management." Employee commitment to RBP is measured with four items based on Hercovitch and Meyer's (2002) commitment to change scales with a minor adaptation. The example item is "I believe in the value of RBP." We measure international donor support including four items. The item of "Funding from international donors is important for our continued use of RBP" is an example. The instrument for leadership support and involvement was developed mainly based on Thompson and Fulla's (2001) and Fernandez and Rainey's (2006) work. The lead-in of the question is 'In my organization, my leaders..." The example item is "Are very much aware of the importance of RBP."

To further refine the survey questionnaire, we conducted five semi-structured, qualitative interviews using the following questions: (1) How does your agency/unit use RBP? (2) What do you see as the most important benefits of RBP in your organization? (3) What are the key success factors of doing RBP in your agency and explain why? The interview instrument was structured in the form of sequential easy-to-hard questions, and either auto-recorded or with the notes taken, and interview transcripts were analyzed.

Also, we conducted a test for common method bias (CMB) in PLS using Lindel and Whitney's (2001) marker variable approach. The maximum shared variance with the other variables of marker variable is only $6.86 \%\left(.262^{2}\right)$, which shows that $\mathrm{CMB}$ is not a significant concern in our data.

\section{Data analysis and key findings}

A framework from the literature review and empirical observations of current RBP in the Vietnamese context was developed and tested using mixed methods with foci on the survey. Quantitative data were analyzed using the Partial Least Squares Structural Equation Modeling (PLS-SEM) technique, whereas qualitative data obtained from in-depth interviews were thematically analyzed and used to refine the survey instruments developed from the literature and prevalidated measurement items. We applied PLS-SEM to investigate how organizational factors impact RBP outcomes due to the following reasons. First, Structural Equation Modeling (SEM) is a powerful statistical technique that is widely recommended to use as an appropriate method in social science (Hair et al, 
2011). Basically, PLS-SEM is similar to regression techniques, but simultaneously tests the measurement model (relationships between a latent variable and its indicator) and structural model (relationships among latent variables) (Verbeeten, 2008). Second, our theoretical model considers the indirect relationship between variables via mediators which can be easily disregarded in standard regression techniques (Moynihan et al, 2011). Third, compared to other SEM techniques, PLS does not require large sample sizes and residual distributions (Chin et al, 2003; Hair et al, 2014). Following Hair et al's (2014) guidance, we subsequently examined the measurement model and the structural model for discriminant and convergent validity and reliability, and for testing hypotheses, respectively.

\section{Measurement model}

Table 2 provides the information on variables and measurement. Items utilized to measure all reflective constructs were highly reliable with all the Cronbach's Alpha $>0.79$, indicator outer loadings were greater than 0.70 , the average variance extracted (AVE) for all variables was higher than the accepted level of 0.5 (Hair et al, 2014), and composite reliability was well above 0.8, demonstrating acceptable convergent validity. In addition, outer loadings of all constructs were higher than all their cross loadings with other constructs (not shown), indicating acceptable discriminant validity.

Table 2

\section{Reliability and convergent validity assessment of the reflective constructs}

\begin{tabular}{|c|c|c|c|c|c|c|}
\hline Constructs & Items & Loading & Sig & Alpha & CR & AVE \\
\hline \multirow[t]{6}{*}{ RBP outcomes (6) } & 1 & .886 & $\mathrm{p}<.001$ & \multirow{6}{*}{.973} & \multirow{6}{*}{.976} & \multirow{6}{*}{.774} \\
\hline & 2 & .904 & $\mathrm{p}<.001$ & & & \\
\hline & 3 & .864 & $\mathrm{p}<.001$ & & & \\
\hline & 4 & .874 & $\mathrm{p}<.001$ & & & \\
\hline & 5 & .907 & $\mathrm{p}<.001$ & & & \\
\hline & 6 & .898 & $\mathrm{p}<.001$ & & & \\
\hline \multirow[t]{4}{*}{ Employee commitment to RBP (4) } & 1 & .914 & $\mathrm{p}<.001$ & \multirow{4}{*}{.907} & \multirow{4}{*}{.941} & \multirow{4}{*}{.843} \\
\hline & 2 & .943 & $\mathrm{p}<.001$ & & & \\
\hline & 3 & .937 & $\mathrm{p}<.001$ & & & \\
\hline & 4 & .903 & $\mathrm{p}<.001$ & & & \\
\hline \multirow[t]{4}{*}{ Leadership support and involvement (4) } & 1 & .810 & $\mathrm{p}<.001$ & \multirow{4}{*}{.887} & \multirow{4}{*}{.918} & \multirow{4}{*}{691} \\
\hline & 2 & .903 & $\mathrm{p}<.001$ & & & \\
\hline & 3 & .838 & $\mathrm{p}<.001$ & & & \\
\hline & 4 & .845 & $\mathrm{p}<.001$ & & & \\
\hline
\end{tabular}




\begin{tabular}{|c|c|c|c|c|c|c|}
\hline Constructs & Items & Loading & Sig & Alpha & CR & AVE \\
\hline \multirow[t]{4}{*}{ Donor support (4) } & 1 & .829 & $\mathrm{p}<.001$ & \multirow{4}{*}{.895} & \multirow{4}{*}{.927} & \multirow{4}{*}{.760} \\
\hline & 2 & .910 & $\mathrm{p}<.001$ & & & \\
\hline & 3 & .912 & $\mathrm{p}<.001$ & & & \\
\hline & 4 & .833 & $\mathrm{p}<.001$ & & & \\
\hline \multirow[t]{4}{*}{ RBP-related training (4) } & 1 & .859 & $\mathrm{p}<.001$ & \multirow{4}{*}{.859} & \multirow{4}{*}{.904} & \multirow{4}{*}{.702} \\
\hline & 2 & .886 & $\mathrm{p}<.001$ & & & \\
\hline & 3 & .814 & $\mathrm{p}<.001$ & & & \\
\hline & 4 & .789 & $\mathrm{p}<.001$ & & & \\
\hline
\end{tabular}

\section{Structural model}

The structural model is assessed by collinearity, the level and significance of the path coefficients and the coefficient of determination $\left(\mathrm{R}^{2}\right)$, effect size $\left(\mathrm{f}^{2}\right)$, predictive relevance $\left(\mathrm{q}^{2}\right)$ (Hair et al, 2014). All constructs in the model have tolerance levels above 0.20 and VIF below the critical value of 5 (not shown). Hence, collinearity among the predictor constructs is not an issue in the structural model. The blindfolding results show that $\mathrm{q}^{2}$ and $\mathrm{f}^{2}$ values are above 0 (not shown), indicating that the exogenous constructs have predictive relevance for the endogenous constructs under consideration. The bootstrapping results show that the majority of path coefficients are significant. As suggested by Fornell (1982), all insignificant relationships were eliminated from the PLS-SEM model to identify equivalent models that fit the data and theory best. Ultimately, we arrived at a final PLS-SEM model specification (see Figure 2). As shown, the PLS-SEM structural model includes path coefficients, significance level ( $\mathrm{p}$-value), and variance explained $\left(\mathrm{R}^{2}\right)$ for each endogenous construct (dependent variable).

Figure 2: Final PLS-SEM structural model



Note: ${ }^{* *} \mathrm{p}<.001,{ }^{\star} \mathrm{p}<.05$ 
The examination of total effects, as shown in Table 3, brought more interesting results. To be specific, it shows the strength of each driver construct that ultimately influences the target construct (RBP outcomes) via the mediating construct "Employee commitment to RBP." Among predictor constructs, employee commitment has the strongest total effect on RBP outcomes (.543), followed by training (.431), and donor support (.302). The results obtained from running bootstrapping show the $\mathrm{R}^{2}$ values of RBP outcomes (.589). In this research model, 58.9\% of the RBP outcomes variation is explained by its relationships with RBP-related training, employee commitment, leadership support and involvement, and donor support.

Table 3

Total effects

\begin{tabular}{|l|c|c|}
\hline & Employee commitment & RBP outcomes \\
\hline Employee commitment & & .543 \\
\hline RBP-related training & .239 & .431 \\
\hline Leadership support and involvement & .182 & .099 \\
\hline Donor support & .557 & .302 \\
\hline $\boldsymbol{R}$ square $\left(\boldsymbol{R}^{2}\right)$ & .694 &. $\mathbf{5 8 9}$ \\
\hline
\end{tabular}

In order to further examine findings of the relationship of organizational variables and RBP outcomes provided by standard PLS-SEM analyses, two advanced analyses were conducted including mediator analysis and importanceperformance matrix analysis (IPMA) (Hair et al, 2014). It is hypothesized that the relationships between the constructs "RBP-related training", "Leadership support and involvement", "Donor support", and RBP outcomes are mediated by employee commitment. To test whether these relationships exist, a necessary condition is the significance of the relationships between these constructs and employee commitment $(.239, .183, .555$ respectively), and between employee commitment and RBP outcomes (.584) (Hair et al, 2014). The bootstrapping results (not shown) indicate the significance of these relationships $(\mathrm{p}<0.05)$. Hence, employee commitment to RBP mediates the relationships between training, leadership support, donor support, and RBP outcomes. The results of IPMA analysis (not shown) show that employee commitment to RBP is of primary importance for creating RBP outcomes, but its performance is lower than the average value of all constructs. Thus, to improve RBP outcomes, the construct of employee commitment to RBP should be emphasized.

Hypothesis testing and significant results on the hypothesized relationships between organizational factors and RBP practices

As suggested by Hair et al (2014) and Kock (2015), to test the significance of hypothesized relationships which serves to test hypotheses, the bootstrapping procedure was conducted. Hypotheses with a significance value of $p<.05$ are con- 
sidered as statistically supported (Hair et al, 2014, Kock, 2015). The bootstrapping results indicate that five out of seven hypothesized relationships (i.e., $\mathrm{H} 2, \mathrm{H} 4$, $\mathrm{H} 4 \mathrm{a}, \mathrm{H} 4 \mathrm{~b}, \mathrm{H} 4 \mathrm{c}$ ) are supported.

As expected, $\mathrm{H} 2$ is accepted, indicating the positive influence of RBP-related training on RBP outcomes. The path coefficient and p-values show that employee commitment has a direct and positive influence on RBP outcomes, providing evidence for supporting $\mathrm{H} 4$. Interestingly, no statistical evidence from the data is found to support the direct relationships between leadership support and involvement as well as donor support and RBP outcomes, hence H1 and $\mathrm{H} 3$ are rejected. However, these two constructs indirectly impact on RBP outcomes via employee commitment, thus $\mathrm{H} 4 \mathrm{~b}, \mathrm{H} 4 \mathrm{c}$ are accepted. The results also show that RBP-related training has an indirect impact on RBP outcomes via employee commitment $(\mathrm{H} 4 \mathrm{a})$ alongside its direct relationship with RBP outcomes as confirmed in $\mathrm{H} 2$.

There are several findings worth noting. Employee commitment has the strongest effect on RBP outcomes. This result supports previous studies indicating the positive association between employee commitment to change and the success or positive outcomes of change initiative (Herscovitch \& Meyer, 2002; Jaros, 2010; Hill, 2012). RBP-related training has both direct and indirect influence on RBP outcomes. This finding agrees with results from previous studies indicating the importance of training in developing and using results-based initiatives successfully (Schraeder et al, 2005; Ohemeng, 2009; De Waal \& Counet, 2009; Hung et al, 2015). Although leadership support and involvement and donor support have no direct relationships with RBP outcomes, they indirectly affect RBP outcomes via employee commitment. A statement by a planning expert from MARD could be one explanation for these insignificant direct relationships with RBP outcomes:

In my own view, the role of international support is normally limited to the initiation phase, this means that once RBP has been adopted in a certain agen$c y$, they are no longer involved. Similarly, top or senior managers are clearly and visibly involved mostly in RBP initiation, but not in its implementation.

Also, most qualitative evidence in this study indicates the crucial role of top managers and international donors in introducing and getting RBP adopted by MARD. For example:

As for top leaders, they mainly demonstrate their strong support and high commitment to this new planning approach [RBP] publicly through their speeches in meetings or conferences, especially in front of international donors and higher management level...even one of our top manager used to strongly stress that "we should have adopted results-based planning 10-15 years ago". To be frank, thanks to these supports, this planning method has been adopted in our Directorate until now.

All related training courses have been provided to civil servants in our Ministry through internationally funded projects 


\section{Discussion and conclusion}

The main objective of this study is to examine the impact of organizational factors on RBP outcomes in a developing country such as Vietnam. The findings show that employee commitment to RBP has a strongly positive and direct relationship with RBP outcomes, followed by RBP-related training, while donor support and leadership support and involvement indirectly affect RBP outcomes via employee commitment. Based on these findings, the study suggests that to improve RBP outcomes, employee commitment should be more emphasized and that leadership support and involvement, international support and effective training can help increase such commitment.

Prior to furthering the discussion on the implications of this study, some limitations from the data and measurements are noted. First, as our study uses questionnaire methodology, the issue of common method bias (CMB) should be considered. Instead of using "hard measures" in this study we used self-report data from public employees to evaluate the RBP outcomes which may not reflect accurately what the actual RBP outcomes are. Most of the measures were developed for the purpose of this study based on the previous research coupled with observations of existing contexts of RBP. Therefore, much remains to be done for further refinement. To minimize the possibility of measurement errors, we conducted a careful research design with pre-survey interviews and questionnaire testing. Also, our test conducted for CMB in PLS-SEM using Lindel and Whitney's (2001) marker variable approach shows that CMB is not a significant concern in our data. Second, our data were collected in Vietnam - a one-party and centralized state with its unique and complex planning system, therefore the findings may not be transferable to other countries. Another source of concern may be the selection of snowball sampling methods that may limit the generalizability of the findings (Brewer \& Miller, 2003; Atkinson, 2001). However, this research was carefully designed and followed strict sampling procedures suggested by the previous researchers (Heckathorn, 1997; Atkinson, 2001), which can minimize this limitation.

The research makes a significant contribution to the performance management literature by providing empirical evidence of the relationships between organizational factors and the outcomes of results-based reforms such as RBP in a context of a developing country. In a developing country such as Vietnam, where development planning is still a vital instrument of policy-making, furthering outcomes is essential to on-going results-based public sector reforms. Despite the initial promising results of RBP, much still needs to be done to overcome the remaining challenges to RBP. Much still needs to be learnt about why results-based reforms and their elements achieve success in some developing countries, but less so in others (Mongkol, 2011). By offering public organizations an insight into the specific factors as a means of furthering RBP, this study has the potential to help increase the chance of successful implementation and widespread use of resultsbased reforms in Vietnam as well as in other developing countries.

Notably, practical experience of RBP in the Vietnamese Ministry of Agricultural and Rural Development shows that donor support is among the organiza- 
tional factors that create RBP outcomes, though indirectly via employee commitment. This suits the fact that the adoption of such a new management approach as RBP in the Vietnamese public sector, like in many developing countries, has been affected by the encouragement (even forces) of various international donors such as WB, UNDP, etc. However, such reform programs are often successful in the short-term rather than in the long-term. Hence, in order to get RBP widely and successfully applied in Vietnam in the long-term, government agencies need to gradually reduce the dependence on international donors in sustaining RBP through increasing the role of leadership at all levels and training, thereby helping enhance employee commitment to RBP. This is possible as Vietnam has a tradition of strong country ownership of its reform programs though it is among the largest recipients of ODA in the world (World Bank, 2007).

The study findings can be very helpful in developing certain training programs to increase the commitment to RBP among public employees, thereby increasing RBP outcomes. To be specific, courses on results-based management with fundamental knowledge and skills of this approach, a considerable amount of time, and the participation of knowledgeable, skillful, and experienced instructors should be part of training or retraining programs for civil servants at all levels. Public leaders, especially at the top level should seriously participate in such training courses even though it is tough to get them to undertake such training. However, if results-based management is added to the national curriculum for the training and retraining of civil servants, it will be easy to persuade leaders to adopt and sustain RBP though they do not receive any support from international donors.

Despite its limitations, our study offers several interesting and promising findings and it does provide several opportunities for future research. Firstly, since some measures of the study constructs, significantly the RBP outcomes, are newly developed based on the literature review and practical observations in the Vietnamese context, it would be of interest if the validity and reliability of these measurements are more rigorously tested in future studies. Secondly, there are several possibilities for the application of these research findings. Specifically, these findings can be applied in other developing settings with the same conditions as those in this research and then a comparison of the findings across contexts can be conducted. Also, future studies could include a larger number of Vietnamese public agencies in their sample to empirically test the generalizability of the research findings towards the whole public sector. Thirdly, more specific and longitudinal research on the practices of RBP in developing settings would provide us with a deeper understanding of RBP itself and the determinants of RBP outcomes as our research uses cross-sectional data. Though pre-survey interviews were conducted as a supplement to surveys, neither of the key variables in our research, especially RBP outcomes, was examined in much depth or breadth.

In conclusion, towards a "whole-of-government managing for results" that is expected to create a more accountable, transparent and effective government, each government agency should start RBP with careful consideration of the organizational factors affecting this planning approach, and then integrate RBP into all the other stages of public sector management (programming, budgeting, implementation, and monitoring and evaluation). 


\section{REFERENCE}

1. Abramson, M.A. \& Lawrence, P.R. (Eds.) (2001). Transforming Organizations. Rowman \& Littlefield.

2. Ariyachandra, T.R. \& Frolic, M.N. (2008). Critical Success Factors in Business Performance Management - Striving for Success. Information Systems Management, vol. 25, no 2, pp. 113-120.

3. Asian Development Bank (2015). Viet Nam: Country Partnership Strategy (2012-2015). Available at: https://www.adb.org/sites/default/files/institutional.../files/ (accessed: 16 June, 2017).

4. Asia-Pacific CoP-MfDR (2011). Framework for Results-based Public Sector Management and Country Cases. Available at: https://www.oecd.org/ dac/peer-reviews/Asia (accessed: 16 June, 2017).

5. Atkinson, R. \& Flint, J. (2001). Accessing Hidden and Hard-to-Reach Populations: Snowball Research Strategies. Social Research Update, vol. 33, no 1, pp. 1-4.

6. Brewer, J.D. \& Miller, R.L. (Eds.). (2003) The AZ of Social Research: a Dictionary of Key Social Science Research Concepts. Sage Publications.

7. Burke, W.W. (2002). Organization Change: Theory and Practice. Sage Publications.

8. Conway, E. \& Monks, K. (2008). HR Practices and Commitment to Change: An EmployeeLevel Analysis. Human Resource Management Journal, vol. 18, no 1, pp. $72-89$.

9. Cox, M., Hanh, T.T., Hung, T. \& Dinh, D. (2011). Paris Declaration/Hanoi Core Statement Phase 2 Evaluation Vietnam Country Evaluation' [online]. Available at: https://www.oecd. org/countries/vietnam/47675183.pdf (accessed: 27 February, 2018).

10. Curristine, T. (2005). Government Performance. OECD Journal on Budgeting, vol. 5, no 1, pp. 127-151.

11. Dang, D.A. (2013). How Foreign Direct Investment Promote Institutional Quality: Evidence from Vietnam. Journal of Comparative Economics, vol. 41, no 4, pp. 1054-1072.

12. De Waal, A.A. \& Counet, H. (2009). Lessons Learned from Performance Management Systems Implementations. International Journal of Productivity and Performance Management, vol. 58, no 4, pp. 367-390.

13. Do, X.T. \& Truong, Q. (2009). The Changing Face of Public Sector Management in Vietnam. In: The Changing Face of Vietnamese Management. London: Routledge, pp. 187-220.

14. Fernandez, S. \& Rainey, H.G. (2006). Managing Successful Organizational Change in the Public Sector. Public Administration Review, vol. 66, no 2, pp. 168-176.

15. Fornell, C. (1982). A second generation of multivariate analysis. 2. Measurement and evaluation (Vol. 2). Praeger Publishers.

16. Forsberg, L.T. \& Kokko, A. (2007). The role of donors in Vietnamese development planning. Stockholm School of Economics Working Paper.

17. Gao, J. (2015). Performance Measurement and Management in the Public Sector: Some Lessons from Research Evidence. Public Administration and Development, vol. 35, no 2, pp. 86-96. 
18. García Moreno, M. \& García López, R. (2010). Managing for Development Results: Progress and Challenges in Latin America and the Caribbean. Inter-American Development Bank.

19. Gerrish, E. (2016). The Impact of Performance Management on Performance in Public Organizations: A Meta-Analysis. Public Administration Review, vol. 76, no 1, pp. 48-66.

20. Gilley, A.M. (2005). The Manager as Change Leader. Greenwood Publishing Group.

21. Hair Jr, J.F., Hult, G.T.M., Ringle, C. \& Sarstedt, M. (2014). A Primer on Partial Least Squares Structural Equation Modeling (PLS-SEM), SAGE Publications.

22. Hair, J.F., Ringle, C.M. \& Sarstedt, M. (2011). PLS-SEM: Indeed, a Silver Bullet. Journal of Marketing Theory and Practice, vol. 19, no 2, pp. 139-152.

23. Heckathorn, D.D. (1997). Respondent-Driven Sampling: A New Approach to the Study of Hidden Populations. Social problems, vol. 44, no 2, pp. 174-199.

24. Heinrich, C.J. (2002). Outcomes-Based Performance Management in the public sector: implications for Government Accountability and Effectiveness. Public Administration Review, vol. 62 , no. 6 , pp. $712-725$.

25. Herold, D.M., Fedor, D.B., Caldwell, S. \& Liu, Y. (2008). The Effects of Transformational and Change Leadership on Employees' Commitment to a Change: A Multilevel Study. Journal of Applied Psychology, vol. 93, no 2, pp. 346.

26. Herscovitch, L. \& Meyer, J.P. (2002). Commitment to Organizational Change: Extension of a Three-Component Model. Journal of Applied Psychology, vol. 87, no 3, pp. 474.

27. Hill, N.S., Seo, M.G., Kang, J.H. \& Taylor, M.S. (2012). Building Employee Commitment to Change across Organizational Levels: The Influence of Hierarchical Distance and Direct Managers' Transformational Leadership. Organization Science, vol. 23, no 3, pp. 758-777.

28. Hung, N.K., Poon, H.Y., Hoa, D.D., Dung, T.N. \& Nguyen, X.N. (2013). Practices and Key Learning from PAR Planning and Implementation at the Provincial Level. Within the framework of the Danish-funded Good Governance and Public Administration Reform Programme Phase 1 (GOPA 1, 2008-2013).

29. Hung, N.K., Poon, H.Y., Hoa, D.D., Dung, T.N. \& Nguyen, X.N. (2015). Experiences and Key Learning from Performance Management System Pilots in Five GOPA Provinces. Within the framework of the Danish-funded Good Governance and Public Administration Reform Programme Phase 2 (GOPA 2, 2012-2015).

30. Jaros, S. (2010). Commitment to Organizational Change: A Critical Review. Journal of Change Management, vol. 10, no 1, pp. 79-108.

31. Kock, N. (2015). Common Method Bias in PLS-SEM: A Full Collinearity Assessment Approach. International Journal of e-Collaboration (IJeC), vol. 11, no 4, pp. 1-10.

32. Mangkol, K. (2011). The Critical Review of New Public Management Model and its Criticisms. Research Journal of Business Management, vol. 5, pp. 35-43.

33. Mayne, J. (2007). Challenges and Lessons in Implementing Results-Based Management. Evaluation, vol. 13, no 1, pp. 87-109.

34. Middleton, S. \& Regan, T. (2015). Performance-Based Planning and Programming in the Context of MAP-21 (No. DOT-VNTSC-FHWA-15-06) [online]. Available at: https://rosap.ntl. bts.gov/view/dot/12154 (accessed: 15 July, 2017). 
35. Ministry of Home Affair (2015). Report on Review of Implementation of Public Administration Reform in the Phase 2011-2015. Hanoi: MOHA.

36. Moynihan, D.P. (2006). Managing for Results In State Government: Evaluating a Decade of Reform. Public Administration Review, vol. 66, no 1, pp. 77-89.

37. Moynihan, D.P., Pandey, S.K. \& Wright, B.E. (2011). Setting the Table: How Transformational Leadership Fosters Performance Information Use. Journal of Public Administration Research and Theory, vol. 22, no 1, pp. 143-164.

38. Nielsen, P.A. (2014). Learning from Performance Feedback: Performance Information, Aspiration Levels, and Managerial Priorities. Public Administration, vol. 92, no 1, pp. 142-160.

39. Nkosi, S.M. (2015). Effects of Training on Employee Commitment, Retention and Performance: A Case Study of a Local Municipality in South Africa. European Journal of Business and Management, vol. 7, no 15, pp. 104-108.

40. Ocen, E., Francis, K. \& Angundaru, G. (2017). The Role of Training in Building Employee Commitment: The Mediating Effect of Job Satisfaction. European Journal of Training and Development, vol. 41, no 9, pp. 742-757.

41. OECD (2013). Managing Aid for Trade and Development Results [online]. Available at: http:// www.oecd-ilibrary.org/development/aid-for-trade-and-development (accessed: 5 December, 2016).

42. OECD-DAC (2007). Sourcebook on Emerging Good Practice in Managing for Development. $2^{\text {rd }}$ edition [online]. Available at: http://www.mfdr.org/Sourcebook.html (accessed: $12 \mathrm{Au}-$ gust, 2017).

43. Ohemeng, F.L.K. (2009). Constraints in the Implementation of Performance Management Systems in Developing Countries: the Ghanaian case. International Journal of Cross Cultural Management, vol. 9, no 1, pp. 109-132.

44. Pham, H.N. (2018). Leadership and Public Sector Reform in Vietnam. Leadership and public sector reform in Asia, pp. 127-149.

45. Poister, T.H., Pasha, O.Q. \& Edwards, L.H. (2013). Does Performance Management Lead to Better Outcomes? Evidence From the US Public Transit Industry. Public Administration Review, vol. 73, no 4, pp. 625-636.

46. Pollitt, C. \& Bouckaert, G. (2003). Evaluating Public Management Reforms: An International Perspective. In: Evaluation in Public-Sector Reform. Concepts and Practice in International Perspective. Cheltenham, pp. 12-35.

47. Rigdon, E.E., Ringle, C.M., Sarstedt, M. \& Gudergan, S.P. (2011). Assessing Heterogeneity in Customer Satisfaction Studies: Across Industry Similarities and Within Industry Differences. In: Measurement and Research Methods in International Marketing, pp. 169-194. Emerald Group Publishing Limited.

48. Schraeder, M., Tears, R.S. \& Jordan, M.H. (2005). Organizational Culture in Public Sector Organizations: Promoting Change through Training and Leading by Example. Leadership \& Organization Development Journal, vol. 26, no 6, pp. 492-502.

49. Tan, S. (2012). Reconsidering the Vietnamese development Vision Of" Industrialisation and Modernisation by 2020 (No. 102). ZEF working paper series. Bonn: Centre for Development Research, University of Bonn. 
50. Thompson, J. \& Fulla, S.L. (2001). Effecting Change in a Reform Context: The National Performance Review and the Contingencies of "Microlevel" Reform Implementation. Public Performance \& Management Review, vol. 25, no 2, pp. 155-175.

51. Van der Voet, J., Kuipers, B.S. \& Groeneveld, S. (2016). Implementing Change in Public Organizations: The Relationship between Leadership and Affective Commitment to Change in a Public Sector Context. Public Management Review, vol. 18, no 6, pp. 842-865.

52. Vasavakul, T. (2006). Public Administration Reform and Practices of Co-Governance: Towards a Change in Governance and Governance Cultures in Vietnam. Active Citizens under Political Wraps: Experiences from Myanmar/Burma and Vietnam.

53. Verbeeten, F.H.M. (2008). Performance Management Practices in Public Sector Organizations. Auditing \& Accountability Journal, vol. 21, no 3, pp. 427-454.

54. Vietnam Ministry of Agricultural and Rural Development (2005). 2006-2010 Five-Year Development Plan in the Agriculture and Rural Development Sector [online]. Available at: http:// vukehoach.mard.gov.vn/default.aspx? (accessed: 7 May, 2018).

55. Vietnam Ministry of Agricultural and Rural Development (2010). 2011-2015 Five-Year Development Plan in the Agriculture and Rural Development Sector [online]. Available at: http:// vukehoach.mard.gov.vn/default.aspx? (accessed: 7 May, 2018).

56. Vu, M.T.T. (2008). Comprehensive Planning: Does It Work? Experiences from Vietnam. Journal of Administration \& Governance (JOAAG), vol. 3, no 2, pp. 18-24.

57. Wallace, E., de Chernatony, L. \& Buil, I. (2013). Building Bank Brands: How Leadership Behavior Influences Employee Commitment. Journal of Business Research, vol. 66, no 2, pp. 165-171.

58. Williams, J.H. \& Cummings, W.K. (2005). Policy-Making for Education Reform in Developing Countries: Contexts And Processes. Vol. 1, R\&L Education.

59. Wong, W. (2013). The Search for a Model of Public Administration Reform in Hong Kong: Weberian Bureaucracy, New Public Management or Something Else? Public Administration and Development, vol. 33, no 4, pp. 297-310.

60. World Bank (2007). The World Bank Annual Report 2007.The World Bank.

61. World Bank (2008). Public Sector Reform: What Works and Why? An IEG Evaluation of World Bank Support, Washington, DC: World Bank, Independent Evaluation Group. 


\section{APPENDIX}

\section{Construct measurement items}

RBP outcomes (Developed for this study but based on: (Asia Pacific CoP-MfDr, 2011), (Middleton \& Regan, 2015)).

1. Increased the clarity of our objectives.

2. Increased quality of our plans.

3. Increased logic of our plans.

4. Increased the feasibility of plans.

5. Increased accountability and transparency in our planning.

6. Improved the evaluation of outcomes against desired objectives.

RBP-related training (Developed for this study but based on: (Mayne, 2007), (Hung et al., 2015)).

1. I was provided by training courses with basic knowledge and skills of RBP (e.g., definition, benefits of results-based planning, problem tree analysis, objective tree analysis, logic model framework for planning).

2. During our training, we were able to ask questions about how we could use RBP.

3. Our trainers provided many excellent and real-life examples of RBP.

4. After receiving training, I can apply knowledge and skills of RBP in my work.

Employee commitment to RBP (Developed for this study but based on: (Hercovitch \& Meyer, 2002)).

1. I believe in the value of RBP.

2. I think that management is making the right decision by introducing RBP.

3. I feel a sense of duty to work toward RBP.

4. I do not think it would be right of me to oppose of RBP.

Leadership support and involvement (Developed for this study but based on: (Thompson \& Fulla, 2001), (Fernandez \& Rainey, 2006)).

1. Are very much aware of the importance of RBP.

2. Are strongly involved in a new planning process.

3. Keep the pressure on operating units to work with RBP.

4. Always support and encourage subordinates to implement the RBP approach.

5. Provide most of the necessary help and resources to enable subordinates to implement RBP.

International donor support (Developed for this study but based on: (Forsberg \& Kokko, 2007), (Hung et al., 2013)).

1. My agency receives support from international donors for implementing RBP.

2. International donors helped us to become familiar with RBP.

3. International donors funded our initial efforts in RBP.

4. Funding from international donors is important for our continued use of RBP. 